\title{
Lutzomyia adiketis sp. n. (Diptera: Phlebotomidae), a vector of Paleoleishmania neotropicum sp. n. (Kinetoplastida: Trypanosomatidae) in Dominican amber
}

\section{George Poinar Jr}

Address: Department of Zoology, Oregon State University, Corvallis, Oregon, 97331, USA

Email: George Poinar - poinarg@science.oregonstate.edu

Published: 15 July 2008

Parasites \& Vectors 2008, I:22 doi:10.1186/1756-3305-1-22
Received: 13 June 2008

Accepted: 15 July 2008

This article is available from: http://www.parasitesandvectors.com/content/I/I/22

(c) 2008 Poinar; licensee BioMed Central Ltd.

This is an Open Access article distributed under the terms of the Creative Commons Attribution License (http://creativecommons.org/licenses/by/2.0), which permits unrestricted use, distribution, and reproduction in any medium, provided the original work is properly cited.

\begin{abstract}
Background: Amber fossils can be used to trace the history of disease-vector associations because microorganisms are preserved "in situ" inside the alimentary tract and body cavity of blood-sucking insects.

Results: Lutzomyia adiketis sp. n. (Phlebotomidae: Diptera) is described from Dominican amber as a vector of Paleoleishmania neotropicum sp. n. (Kinetoplastida: Trypanosomatidae). The fossil sand fly differs from all previously described extinct and extant members of the genus by the following combination of characters: Sc forked with the branches meeting the costa and radius veins; wing L/ $W$ value of 4.1 ; a $\delta$ value of 18 ; a ratio $\beta / \alpha$ value of 0.86 , and the shape and size of the spatulate rods on the ninth sternite. The trypanosomatid is characterized by the structure of its promastigotes, amastigotes and paramastigotes and its transmission by an extinct species of sand fly.

Conclusion: Morphological characters show that the fossil sand fly is a new extinct species and that it is host to a digenetic species of trypanosomatid. This study provides the first fossil evidence that Neotropical sand flies were vectors of trypanosomatids in the mid-Tertiary (20-30 mya).
\end{abstract}

\section{Background}

Moth flies (Psychodidae) and sand flies (Phlebotomidae) are primitive Diptera [1] often treated as subfamilies [2]. The fossil record of sand flies dates back to Early Cretaceous Lebanese [3,4] and Burmese amber [5]. The Burmese amber sand fly, Palaeomyia burmitis Poinar [5] was transmitting Paleoleishmania protera Poinar \& Poinar [6,7], the first described fossil digenetic trypanosomatid parasite. The present study describes a second species of Paleoleishmania carried by an extinct species of Lutzomyia sand fly in Dominican amber.

\section{Results}

Description of vector

Family Phlebotomidae Kertész 1903

Genus Lutzomyia França 1924

Lutzomyia adiketis sp.n. (Figs. 1, 2, 3, 4)

Length $=1.3 \mathrm{~mm}$; body, legs and antennae light brown .

Head; Length, $315 \mu \mathrm{m}$; eye bridge absent; length of proboscis, $202 \mu \mathrm{m}$; maxillary palp extending well beyond tip of proboscis; length of maxillary palp, $544 \mu \mathrm{m}$; palpal for- 


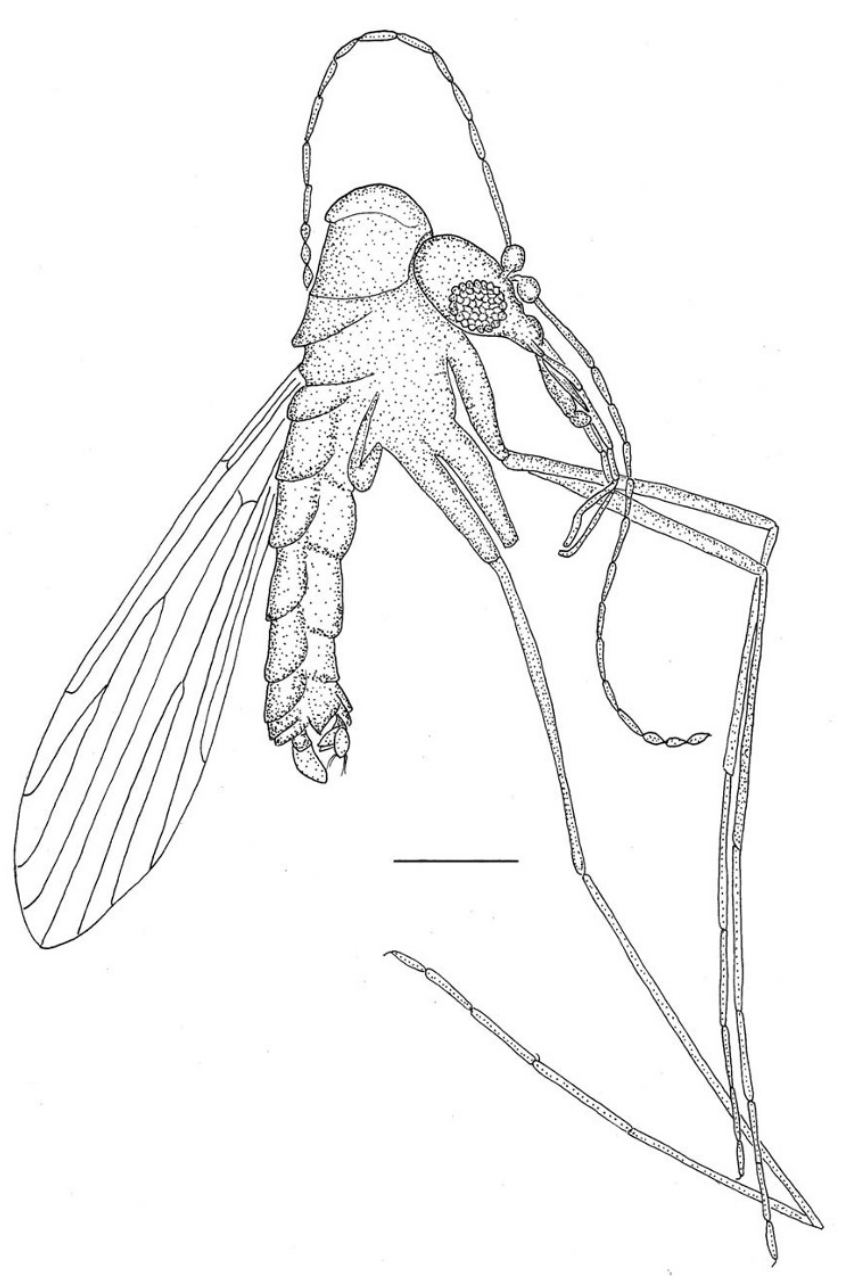

Figure I

Drawing of Lutzomyia adiketis showing wing venation. Bar $=270 \mu \mathrm{m}$.

mula 1-4-2-3-5; Newstead's scales in oval area on basal half of $3^{\text {rd }}$ palpomere; lengths of palpomeres; $1,44 \mu \mathrm{m} ; 2$, $89 \mu \mathrm{m} ; 3,120 \mu \mathrm{m} ; 4,82 \mu \mathrm{m} ; 5,209 \mu \mathrm{m}$; ratio of palp segments, $1 / 2=0.49 ; 2 / 5=0.43 ; 4 / 2=0.64 ; 1 / 5=0.21 ; 3 / 5$ $=0.57 ; 4 / 5=0.39 ; 1 / 3=0.37$; flagellomeres 14 , fusiform; scape short, stout; pedicel globular, terminal 3 segments subequal, shorter and broader than remainder; lengths of antennomeres (in microns) 1, 38; 2, 63 (60); 3, 171 (171); 4, 92 (92); 5, 82 (89); 6, 86 (79); 7, 82 (82); 8, 79 (76); 9, $86(82) ; 10,82(82) ; 11,76(79) ; 12,75$ (83); 13, $81(68) ; 14,51(57) ; 15,41(48) ; 16,41$ (41) (terminal spine on segment $16,10(10)$; ascoids absent on flagellomeres; cibarium not visible.

\section{Thorax}

Length $=441 \mu \mathrm{m}$; wing with Sc forked, one branch reaching costa, other branch reaching $\mathrm{R}_{1}$; Rs four-branched

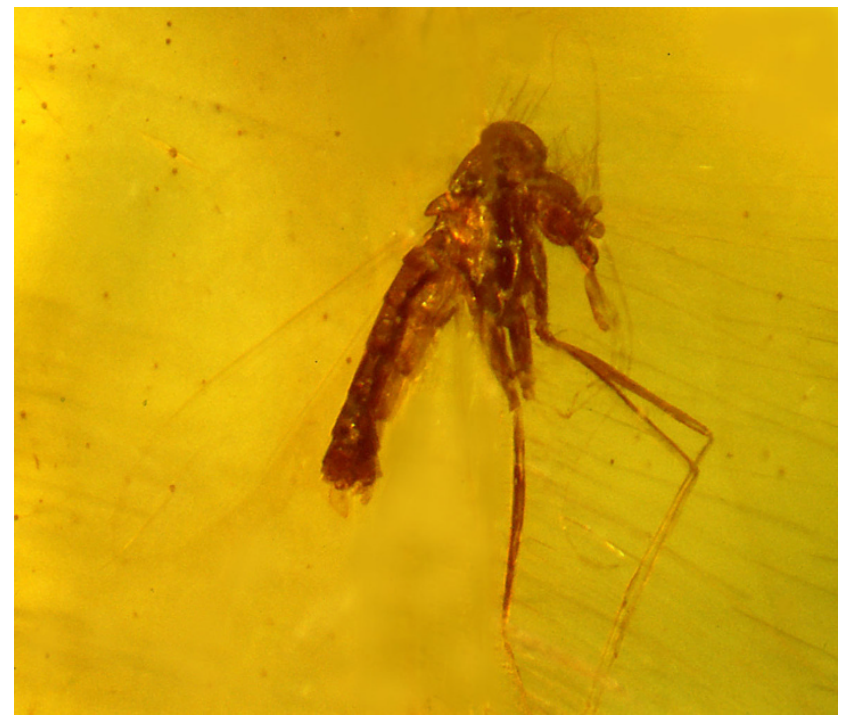

Figure 2

Habitus of Lutzomyia adiketis. Bar $=240 \mu \mathrm{m}$.

with all branches extending to wing margin; Rs shorter than $\mathrm{R}_{2-4} ; \mathrm{R}_{1}$ as long as $\mathrm{R}_{2+3} ; \mathrm{R}_{2-4}$ longer than $\mathrm{R}_{2+3}$; vein $R_{2}$ longer than $R_{2+3}$; veins $S c, R_{1}, R_{2}$ and $R_{3}$ noticeably curved anteriorly at costa ( $R_{1}$ perpendicular to costa), $R_{5}$ straight, veins $M_{1}$ and $M_{2}$ curved posteriorly at costa, vein $\mathrm{CuA}_{2}$ meets wing margin distal to $\mathrm{R}_{2+3}$ fork; termination of $\mathrm{R}_{1}$ distal to fork of $\mathrm{R}_{2+3}$; wing long and narrow, length $1.23 \mathrm{~mm}$, width $0.30 \mathrm{~mm}, \mathrm{~L} / \mathrm{W}=4.1$; wing values, $\alpha=$ $246, \beta=211, \delta=18, \gamma=243$; wing ratio values, $\beta / \alpha, 0.86$; $\gamma / \alpha, 0.98 ; \delta / \beta, 0.09 ; \beta / \gamma, 0.87$; membrane hyaline, main veins and wing surface bearing microtrichia; hind femora lacking teeth, length metafemur $=662$, forefemur $=580$; metatibia $=857$, protibia $=580$; length metatarsomeres, 1 $=454,2=233,3=158,4=126,5=76$; length protarsomeres, $1=315$ (328), $2=189$ (183), $3=126$ (126), $4=$ 113 (107), 5 = 50 (50); tarsal claws paired, simple, thin, small, curved sharply at base, length 18-23 $\mu \mathrm{m}$; spermatheca and associated reproductive structures not visible.

\section{Abdomen}

Abdomen extended, ten segments clearly visible; length, $800 \mu \mathrm{m}$; cerci $116 \mu \mathrm{m}$ long and $54 \mu \mathrm{m}$ wide; lobes on eight sternite $48 \mu \mathrm{m}$ in length; spatulate rods $41 \mu \mathrm{m}$ in length.

Male. - unknown

Type specimen. - Holotype female in Dominican amber deposited in the Poinar amber collection (accession \# P3-5) maintained at Oregon State University. 


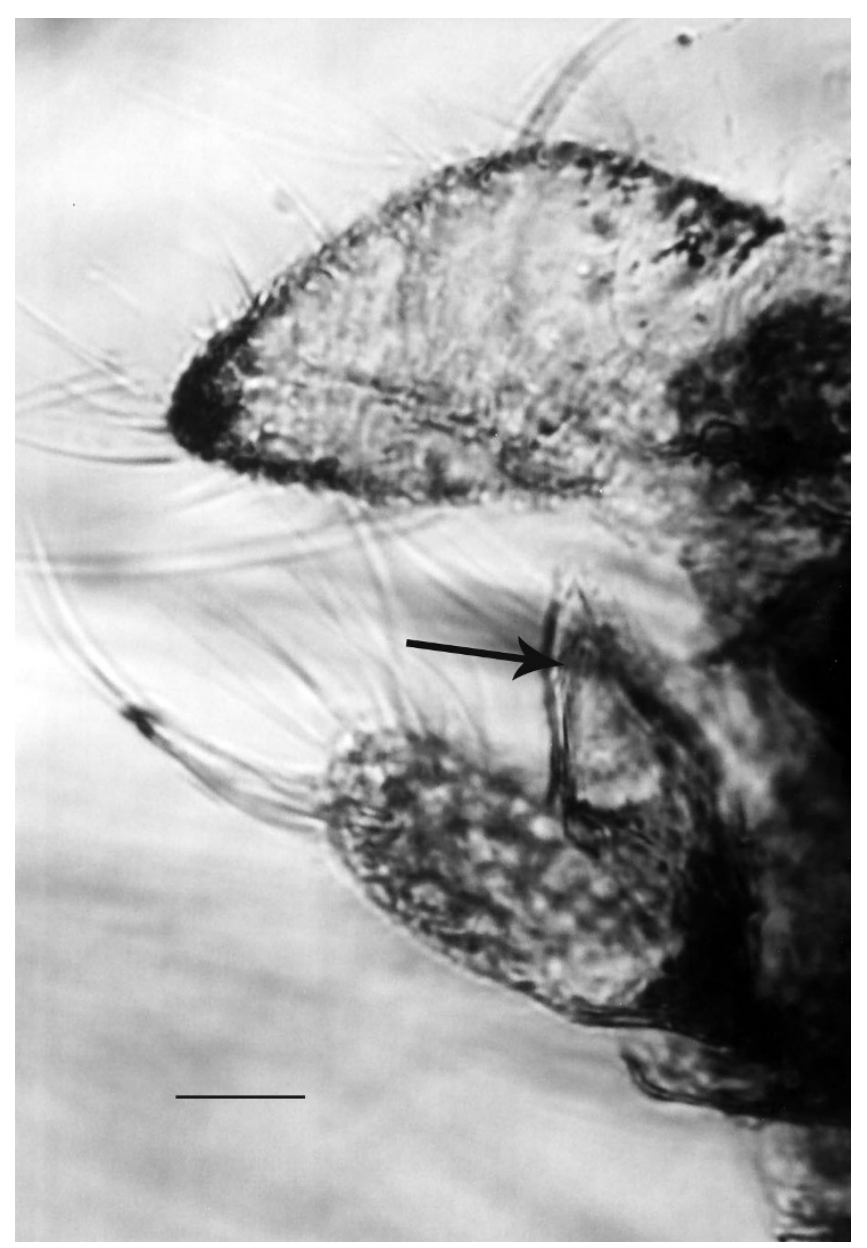

Figure 3

Terminalia of Lutzomyia adiketis. Arrow shows spatulate rods. Bar $=24 \mu \mathrm{m}$.

Etymology. - adiketis is from the Greek "adikos, which means injurious.

\section{Description of Trypanosomatid}

Inside the alimentary tract of $L$. adiketis were hundreds of promastigotes of a trypanosomatid parasite, some of which had entered the hemocoel of the fly. Amastigotes, promastigotes and paramastigotes occurred in the proboscis of the sand fly. This trypanosomatid is provisionally described below as a new species in the genus Paleoleishmania Poinar \& Poinar [6], a collective genus established for fossil digenetic trypanosomatids associated with sand flies.

Phylum Euglenozoa Cavalier-Smith 1981;

Class Kinetoplastea Honigberg 1963;

Order Kinetoplastida Honigberg 1963;

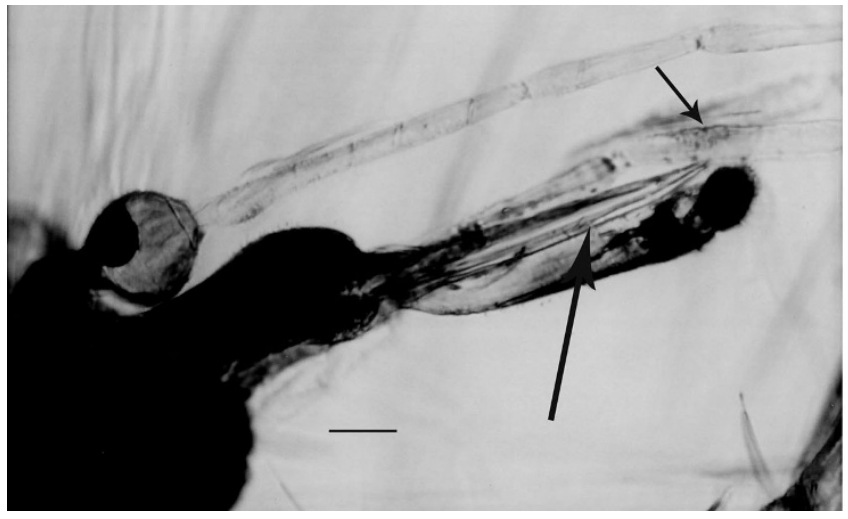

Figure 4

Head of Lutzomyia adiketis. Small arrow shows Newstead's scales on base of third palpomere. Large arrow shows mandibles. Bar $=32 \mu \mathrm{m}$.

Family Trypanosomatidae Dolfein 1901

Genus Paleoleishmania Poinar \& Poinar 2004

Paleoleishmania neotropicum sp. n. (Figs. 5, 6, 7, 8, 9, 10, 11)

Promastigotes $(\mathrm{N}=20)$ Flagellated stages containing nuclei and kinetoplasts; ranging from $6-10 \mu \mathrm{m}$ in length, $1-3 \mu \mathrm{m}$ in width and with flagella ranging from $6-11 \mu \mathrm{m}$ in length (Figs. 5, 6, 7, 8).

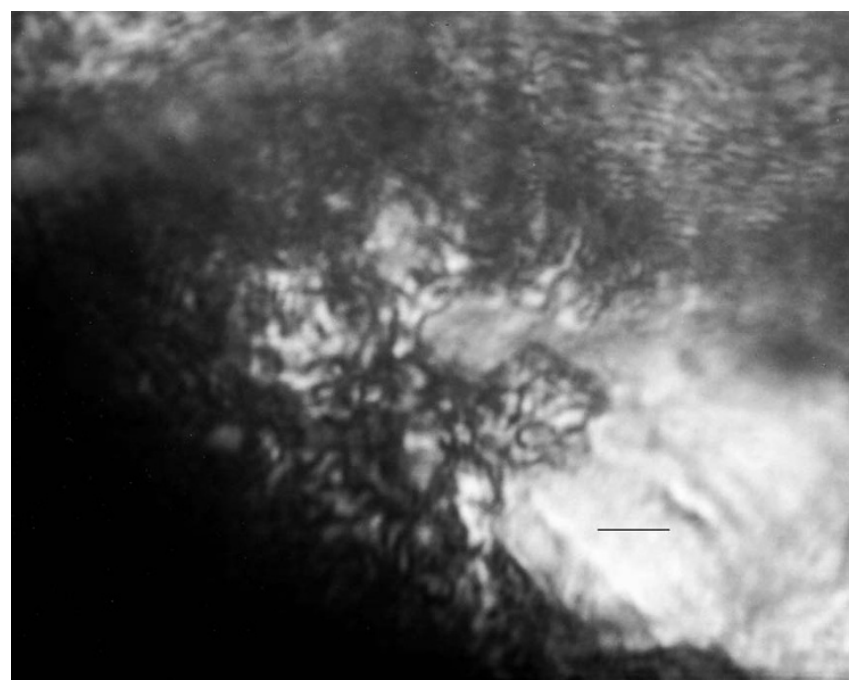

Figure 5

Promastigotes of Paleoleishmania neotropicum in the foregut of Lutzomyia adiketis. Bar $=7 \mu \mathrm{m}$. 


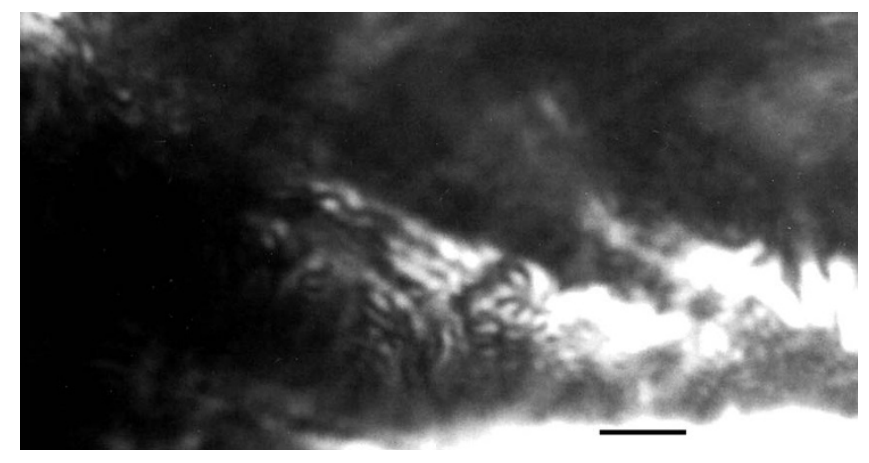

Figure 6

Promastigotes of Paleoleishmania neotropicum in the midgut of Lutzomyia adiketis. Bar $=7 \mu \mathrm{m}$.

Amastigotes $(\mathrm{N}=20)$ Spherical to oval, containing nuclei and kinetoplasts, ranging between $4-7 \mu \mathrm{m}$ in greatest diameter (Figs. 9, 10).

Paramastigotes $(\mathrm{N}=4)$ Oval, relatively short, 3-5 $\mu \mathrm{m}$ in length and 2-4 $\mu \mathrm{m}$ in width, with adjacent nuclei and kinetoplasts; flagella long (10-20 $\mu \mathrm{m})$ (Fig. 11).

Locality

Amber mine in the Cordillera Septentrional of the Dominican Republic.

\section{Host}

The insect host, Lutzomyia adiketis (Diptera: Phlebotomidae), is described in the present work. The vertebrate host is unknown.

\section{Discussion}

\section{Sand fly vector}

The absence of an eye bridge, fusiform flagellomeres, Rs four branched, 2 longitudinal veins present between the radial and medial forks and $A_{1}$ absent, place the fossil in the Phlebotomidae $[2,8]$. The species shares many characters found in the extant subgenera Lutzomyia França and Pintomyia Costa Lima 1932, however the latter genus is

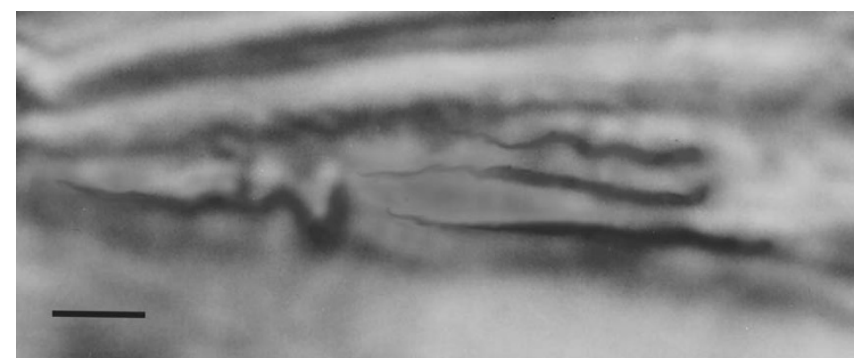

Figure 8

Four promastigotes of Paleoleishmania neotropicum in the proboscis of Lutzomyia adiketis. Bar $=4 \mu \mathrm{m}$.

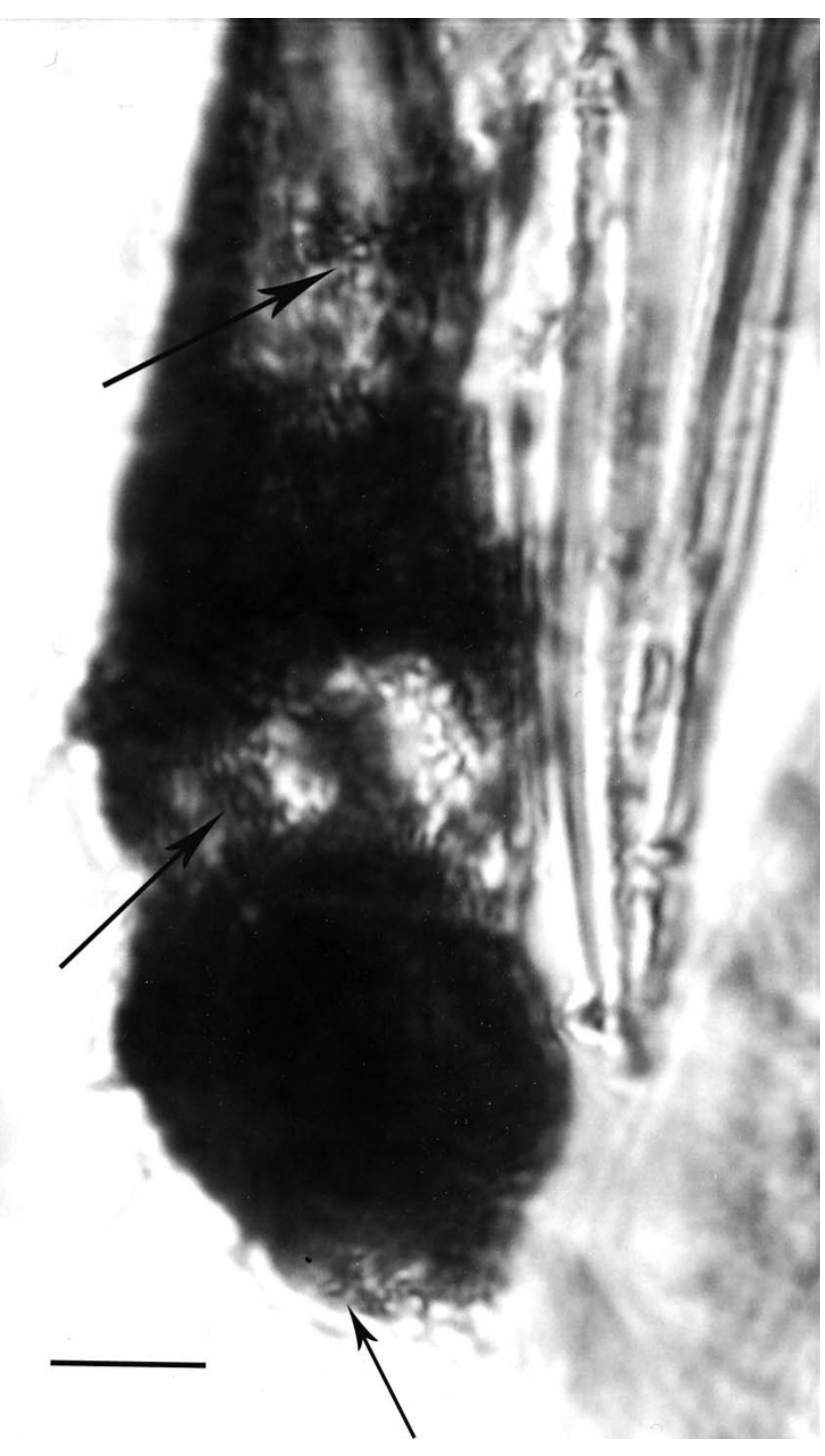

Figure 7

Promastigotes of Paleoleishmania neotropicum in the proboscis (arrows) of Lutzomyia adiketis. Bar $=20 \mu \mathrm{m}$.

characterized by a row of spines on the femur, which the fossil does not possess, thus it is tentatively assigned to the subgenus Lutzomyia. Lutzomyia adiketis differs from all previously described Dominican amber sand flies by its forked Sc vein, a previously used diagnostic character [35 ] and a character that occurs on some members of the subgenus Lutzomyia [9].

Four different configurations of the Sc vein exist in sand flies [9]. The Sc vein can be free, with the distal end not connected to either the costa or R1, as occurs in the Dominican amber Pintomyia paleotownsendi Andrade Filho et al. [10] and Pintomyia falcaorum Brazil et al. [11], Sc can meet the costa vein, as in the Dominican amber $P$. paleot- 


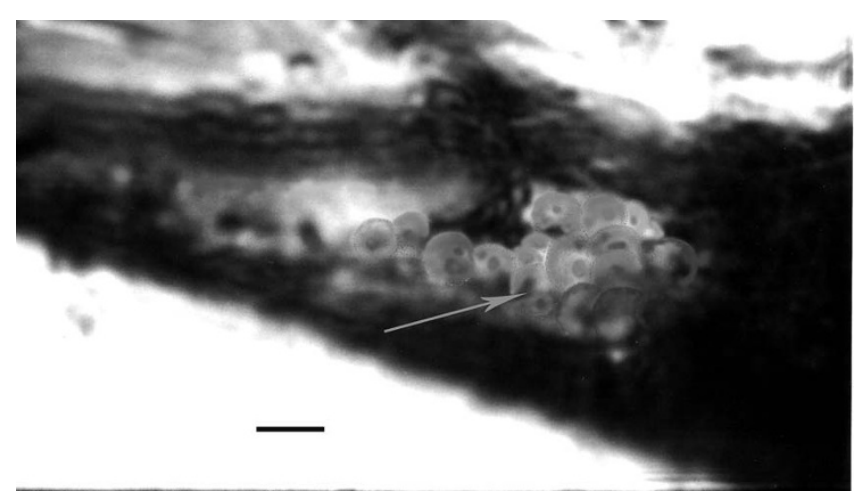

Figure 9

Cluster of amastigotes (arrow) of Paleoleishmania neotropicum in the proboscis of Lutzomyia adiketis. The large dark areas correspond to nuclei, while the smaller ones to kinetoplasts. Bar $=7 \mu \mathrm{m}$.

richia Andrade Filho et al. [12] or the Sc can meet $\mathrm{R}_{1}$, as in the Dominican amber Pintomyia brazilorum Andrade Filho et al. [13], P. killickorum Andrade Filho et al. [14] and all five species described by Peñalver \& Grimaldi [15]. The fourth condition, where Sc forks distally, uniquely occurs only on L. adiketis, among the described Dominican amber fossils.

In addition to the forked Sc vein, the lengths of the papal segments, especially the second, fourth and fifth, the ratio of palpal segment 1 to palpal segment 2, the length/width ratio (4.1) of the wing and values of $\alpha, \beta, \delta, \gamma$, on L. adiketis differ from corresponding values of the five species of Peñalver \& Grimaldi [15]. In order to exclude intraspecific variation due to size alone, ratios were found to be more useful than the actual values in several cases. Thus the ratio $\beta / \alpha(0.86)$ in $L$. adiketis (compared to a range of $0.57-0.71$ in the species of Peñalver \& Grimaldi [15]) and

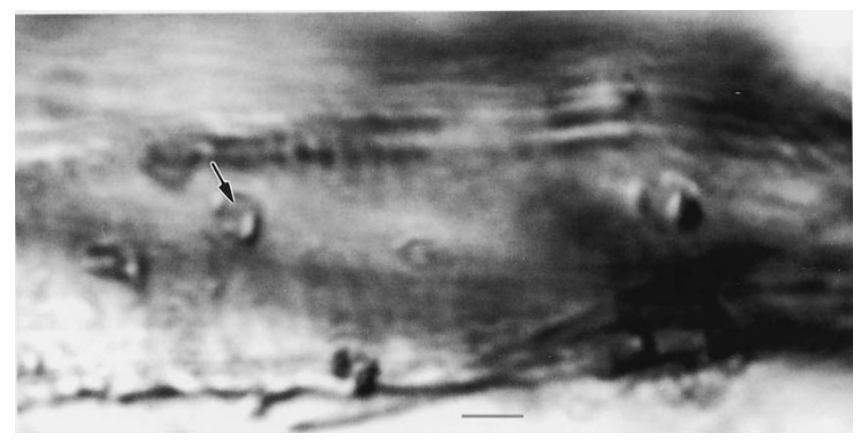

\section{Figure 10}

Amastigotes of Paleoleishmania neotropicum in the proboscis of Lutzomyia adiketis. Arrow shows amastigote with nucleus and kinetoplast. Bar $=7 \mu \mathrm{m}$.

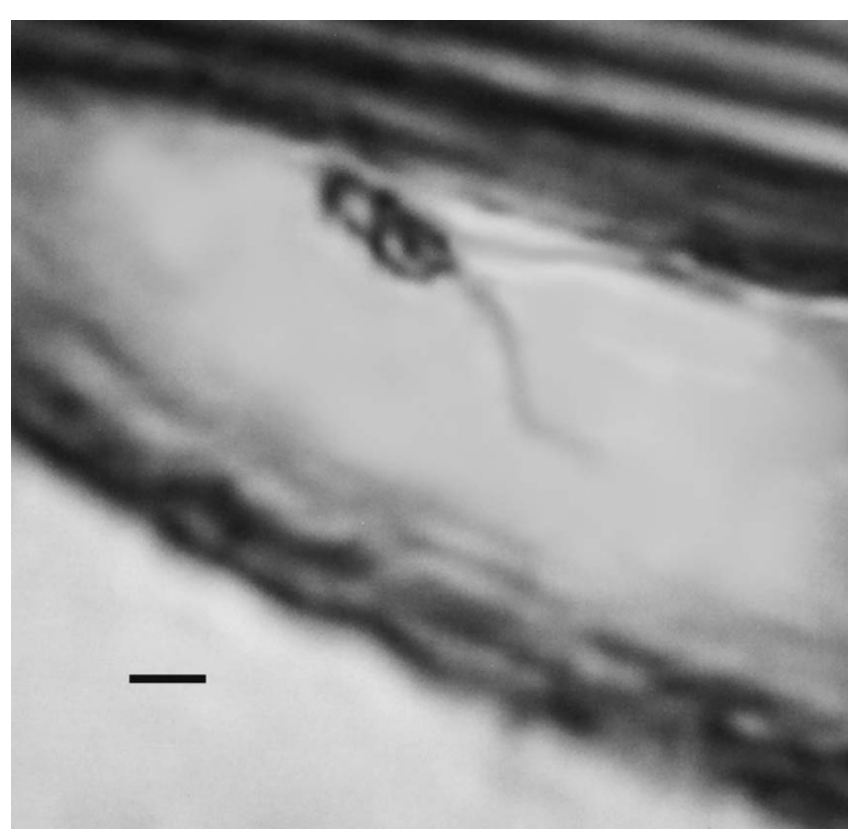

Figure I I

Two paramastigotes of Paleoleishmania neotropicum in the proboscis of Lutzomyia adiketis. Note long flagella. Bar $=5 \mu \mathrm{m}$.

the ratio $\delta / \beta,(0.09)$ in $L$. adiketis (compared to the range of 0.14-0.38 in the species of Peñalver \& Grimaldi [15]) distinguishes $L$. adiketis from the latter species.

Some extant sand flies in the subgenus Lutzomyia also have a forked Sc vein [9], however they can be distinguished from $L$. adiketis by the following characters. In Lutzomyia alencari Martins, Souza \& Falcão, vein $\mathrm{R}_{1}$ meets the costa at the same distance from the wing base as $\mathrm{CuA}_{2}$ meets the wing margin. In L. adiketis, $\mathrm{CuA}_{2}$ meets the wing margin distal to the termination or $\mathrm{R}_{1}$. The wing ratio $\delta / \beta$ can be used to separate L. adiketis (0.09) from L. gasparviannai Martens, Godoy \& Silva (0.57), L. ischyracantha Martens, Falcão \& Silva (0.00) and L. ischnacantha Martins, Sousa \& Falcão (0.89). The ratio of the length of $\mathrm{R}_{2+3}$ to $\mathrm{R}$ ${ }_{2}$ in L. gaminarai (Cordero, Vogelsong \& Cossio)(0.86) is larger than the same ratio in L. adikites (0.74).

There are only two extant species of Lutzomyia found in the Dominican Republic [L. cayennensis hispaniolae (Fairchild \& Trapido) and L. christophei (Fairchild \& Trapido)], both of which belong to the Verrucarum species group [9]. None of the species in this group have forked Sc veins, which separates them from $L$. adiketis.

It is unfortunate that characters of the female external genitalia are so little used in the systematics of the group, even though their diagnostic importance was demonstrated by Mukhopadhyay and Ghosh [16]. The size and shape of 
the cerci, lobes on the $8^{\text {th }}$ sternite and spatulate rods on the ninth sternite could serve as diagnostic characters. The spatulate rods on $L$. adiketis are quite distinctive and similar rods have not been observed on any other amber sand flies examined by the author.

Extant species of Lutzomia are restricted to the New World and their host range is quite extensive, including over 30 families of mammals, birds, reptiles and amphibians [17]. Several extant members of the subgenus Lutzomyia feed on humans and are proven vectors of Leishmania infantum chagasi, the causal agent of American visceral leishmaniasis [9]. The vertebrate host of $L$. adiketis is unknown.

\section{Trypanosomatid}

A single, anteriorly directed flagellum, compact kinetoplast and nucleus places $P$. neotropicum in the family Trypanosomatidae. The presence of amastigotes is evidence that $L$. neotropicum is digenetic, since in Leishmania, amastigotes are only formed in the vertebrate host and there are no known monogenetic flagellates of sand flies [18]. Paramastigotes (metacyclic stages), which are produced inside the gut of the sand fly, also are only infective to vertebrates [18-23]. The flagella always emerged from the anterior end of the flagellates and were not attached to the body along part of most of their length by undulating membranes. Thus, it is unlikely that the fossils belong to the monogenetic genus Blastocrithidia Laird, since the epimastigote stage dominates the life cycle and it has never been recovered from sand flies [18]. Species of Endotrypanum Mensal \& Brimont, which are vectored by sand flies and form promastigotes and amastigotes in the vector [18], are restricted to sloths today and all sloth remains in Hispaniola are from Quaternary cave deposits [24]. If sloths were absent in Hispaniola during the mid-Tertiary when Dominican amber was formed, it would have been impossible for Lutzomyia adiketis to acquire Endotrypanum. It is also unlikely that the flagellates belong to the related genus Phytomonas Donovan since extant species only occur naturally in plant-feeding bugs (Hemiptera)[18].

No vertebrate blood cells were found in the sand fly, however these would be very difficult to detect in the thoracic gut of the intact insect. The round amastigotes of Paleoleishmania neotropicum are similar in size $(4-7 \mu \mathrm{m})$ and morphology to those of extant species of Leishmania [1921,23 . Since amastigotes are normally ingested with the blood meal and pass into the midgut of feeding sand flies, the amastigotes in the fossil proboscis may have arrived in that location immediately after the fossil sand fly finished feeding and became entombed in resin. The amastigotes may even have been multiplying in that location since in Leishmania chagasi, a cycle of amastigote division may occur before or even concurrently with the transformation of amastigotes into promastigotes [21]. Another possibil- ity is that the amastigotes were regurgitated into the proboscis while the sand fly was struggling to escape from the resin.

Promastigotes of extant Leishmania spp. vary from 6 to 24 $\mu \mathrm{m}$ in length (excluding the flagellum) [19-21], which are within the size range of those reported here $(6-10 \mu \mathrm{m})$. The promastigotes in the proboscis of L. adiketis (Fig. 9) could have developed from amastigotes or they could be "infective promastigotes", similar to those of Leishmania chagasi, which occur in the mouthparts (ventral surface of the labrum-epipharynx) of Lutzomyia longipalpis [21]. However, it is also possible that the promastigotes in the proboscis were acquired directly from the vertebrate, since in reptilian hosts, the stages imbibed can be either amastigotes and/or promastigotes $[25,26]$.

The paramastigotes in the proboscis of L. adiketis (Fig. 11) probably developed from an earlier blood meal. Female sand flies are capable of living a month or more [17] and normally engorge blood at least twice during their lifetime, with a batch of eggs laid after each blood meal [25].

The main diagnostic characters of $P$. neotropicum at this time are the structure of the amastigotes, promastigotes and paramastigotes, and its association with the extinct sand fly, Lutzomyia adiketis, in Dominican amber.

Fossil evidence has provided a possible scenario of how sand fly-trypanosomatid associations evolved [28-30]. Free-living trypanosomatids that were associated with a fungal food source also occurred in the alimentary tract of a sand fly larva in Burmese amber. It is postulated that these flagellates were carried transtadially into the adult stage and then transmitted to vertebrates. The establishment of the parasites in the vertebrate and their subsequent re-acquisition by adult sand flies is undoubtedly a rare event and would only occur under ideal conditions. It is unknown whether Leishmania originated in the New or Old World [31,32]. If the above evolutionary pattern of flagellate acquisition is correct, different strains of trypanosomatids could have appeared at different localities and times over the past 100 or so million years. The 100 million year-old Burmese amber sand fly-trypanosomatid, $P$. proterus $[6,7]$ undoubtedly arose independently from $P$. neotropicum, which could well be the progenitor to one or more of the Neotropical Leishmania clades.

\section{Conclusion}

Fossil vertebrate parasites inside insect vectors in amber provide us with a time and place record of diseases affecting terrestrial organisms $[27,29,33,34]$. 
The present study provides the first fossil evidence that Neotropical sand flies were vectors of trypanosomatids in the mid-Tertiary. Lutzomyia adiketis, in Dominican amber, is an extinct species of sand fly that was carrying the trypanosomatid Paleoleishmania neotropicum. It is possible that $P$. neotropicum is a progenitor of at least one of the several extant Neotropical Leishmania clades.

\section{Methods \\ Specimens}

The amber piece containing the fossil sand fly with the trypanosomatids is oval in outline, measuring $18 \mathrm{~mm}$ along the long axis, $12 \mathrm{~mm}$ along the short axis and $2 \mathrm{~mm}$ in thickness. The sand fly is well preserved but both middle legs and the left hind leg are detached, as are almost all hairs from the antennae. Remains of these, along with many body hairs, are positioned behind the fossil, indicating that the sand fly struggled forward to free itself from the resin. The alimentary track was ruptured, allowing some flagellates in the gut to leak into the hemocoel. Observations, drawings and photographs were made with a Nikon SMZ-10 R stereoscopic microscope and Nikon Optiphot compound microscope (with magnifications up to $1050 \times$ ). Some of the photographs were enhanced in Adobe Photoshop.

\section{Locality}

The amber containing the fossils was mined in the northern mountain range (Cordillera Septentrional) of the Dominican Republic between Puerto Plata and Santiago. Dating of Dominican amber is controversial, with the youngest proposed age of 20-15 mya based on foraminifera [35] and the oldest as 45-30 mya based on coccoliths [36]. Most of the amber is secondarily deposited in turbiditic sandstones of the Upper Eocene to Lower Miocene Mamey Group [37].

\section{Source}

Dominican amber was formed by the extinct legume tree, Hymenaea protera Poinar [38] and the original landscape was considered to be a moist, tropical forest [39]. Terminology in the description follows that presented in the "Manual of Nearctic Diptera" [40].

\section{Declaration of competing interests}

The author declares that he has no competing interests.

\section{Acknowledgements}

I thank Art Boucot and Roberta Poinar for reading earlier drafts of the manuscript and R. L. Jacobson for references and comments.

\section{References}

I. Williams P: Relationships of Phlebotomine sand flies (Diptera). Mem Inst Oswaldo Cruz 1993, 88: 177-183.

2. Quate LW, Vockeroth JR: Psychodidae. In Manual of Nearctic Diptera Volume I. Edited by: McAlpine J. Ottawa: Agriculture Canada, Research Branch, Monograph 27; 1981:293-300.
3. Hennig W: Psychodidae (Phlebotominae), mit einer kritischen Übersicht über das phylogenetische System der familie und die bisher beschriebenen Fossilien (Diptera). Stuttgarter Beiträge Naturk 1972, 24 I: I-69.

4. Azar D, Nel A, Solignac M, Paicheler J-C, Bouchet F: New genera and species of psychodoid flies from the Lower Cretaceous amber of Lebanon. Palaeontology 1999, 42: I I0I-II 36.

5. Poinar GO Jr: Palaeomyia burmitis (Diptera: Phlebotomidae), a new genus and species of Cretaceous sand flies with evidence of blood-sucking habits. Proc Entomol Soc Washington 2004, 106:598-605.

6. Poinar GO Jr, Poinar R: Paleoleishmania proterus n. gen., n. sp., (Trypanosomatidae: Kinetoplastida) from Cretaceous Burmese amber. Protist 2004, 155:305-310.

7. Poinar GO Jr, Poinar R: Evidence of Vector-Borne Disease of Early Cretaceous Reptiles. Vector-borne Zoonotic Dis 2004, 4:28I-284.

8. Lewis DJ: Phlebotomidae and Psychodidae (Sand-flies and Moth-flies). In Insects and Other Arthropods of Medical Importance Edited by: Smith KGV. London, The Trustees of the British Museum (Natural History); 1973: 155- 179.

9. Young DC, Duncan MA: Guide to the identification and geographic distribution of Lutzomyia sand flies in Mexico, the West Indies, Central and South America (Diptera: Psychodidae). Mem Amer Entomol Inst 1994, 54: I-88I.

10. Andrade Filho JD, Falcão AL, Galati AB, Brazil RP: Pintomyia (Pifanomyia) paleotownsendi, a new sand fly form the Miocene amber of Dominican Republic (Diptera: Psychodidae: Phlebotominae). Mem Inst Oswaldo Cruz 2006, I0 I(Suppl II):57-58.

II. Brazil RP, Andrade Filho JD: Description of Pintomyia (Pifanomyia) falcaorum sp. n. (Diptera: Psychodidae: Phlebotominae), a fossil sand fly from Dominican amber. Mem Inst Oswaldo Cruz 2002, 97:50I-503.

12. Andrade Filho JD, Brazil RP, Falcão AL, Galati EAB: Description of Pintomyia (Pifanomyia) paleotrichia, a Miocene period new species from the Dominican Republic (Diptera: Psychodidae: Phlebotominae). Mem Inst Oswaldo Cruz 2007, 102:901-903.

13. Andrade Filho JD, Galati AB, Falcão AL: Description of Pintomyia (Pifanomyia) brazilorum sp. nov. a new fossil species from the Dominican Republic (Diptera: Psychodidae: Phlebotominae). Mem Inst Oswaldo Cruz 2006, 101:141-142.

14. Andrade Filho JD, Falcão AL, Brazil RP: A new phlebotomine fossil species Trichopygomyia killickorum sp. n. (Diptera: Psychodidae), found in the Dominican Republic amber. Parasite 2004, I I:7|-73.

15. Penalver E, Grimaldi D: Assemblages of mammalian hair and blood-feeding midges (Insecta: Diptera: Psychodidae: Phlebotominae) in Miocene amber. Trans Royal Soc Edinburgh: Earth Sci 2005, 96: I77-195.

16. Mukhopadhyay J, Ghosh KN: Diagnostic importance of female external genital structure of Phlebotomine sand flies (Diptera: Psychodidae) as observed by scanning electron microscopy. Mem Inst Oswaldo Cruz 1997, 92:57-6I.

17. Christensen HA, Fairchild GB, Herrer A, Johnson CM, Young DG, de Vasquez A-M: The ecology of cutaneous Leishmaniasis in the Republic of Panama. J Med Entomol 1983, 20:463-484.

18. Vickerman K: Order Kinetoplastea Honigberg. In An illustrated Guide to the Protozoa 2nd edition. Edited by: Lee JJ, Leidale GF, Bradbury P. Lawrence, Kansas: Society of Protozoologists; 2000:1 I59-1 I80.

19. Walters LL, Modi GB, Tesh RB, Burrage T: Host-parasite relationship of Leishmania mexicana mexicana and Lutzomyia abonnenci (Diptera: Psychodidae). Amer J Trop Med Hygiene 1987, 36:294-314.

20. Walters LL, Chaplin GL, Modi GB, Tesh RB: Ultrastructural biology of Leishmania (Viannia) panamensis (= Leishmania braziliensis panamensis) in Lutzomyia gomezi (Diptera: Psychodidae): a natural host-parasite association. Amer J Trop Med Hygiene 1989, 40:19-39.

21. Walters LL, Modi GB, Chaplin GL, Tesh RB: Ultrastructural development of Leishmania chagasi in its vector, Lutzomyia longipalpis (Diptera: Psychodidae). Amer J Trop Med Hygiene 1989, 41:295-317.

22. Perfilev PP: Phlebotomidae (Sandflies). In Fauna of U.S.S.R. (Diptera) Volume 33. Moscow: Akademiya Nauk SSSR; 1968:I-363. 
(Translated from Russian by the Israel program for scientific translations, Jerusalem)

23. Plorde JJ: Flagellates. In Medical Microbiology 2nd edition. Edited by: Sherris JC. New York: Elsevier; 1990:729-748.

24. White JL, MacPhee RDE: The sloths of the West Indies: A systematic and phylogenetic review. In Biogeography of the West Indies: Patterns and Perspectives 2nd edition. Edited by: Woods CA, Sergile FE. Boca Raton: CRC Press; 200I:20I-235.

25. Killick-Kendrick R: Biology of Leishmania in phlebotomine sandflies. In Biology of the Kinetoplastida Volume 2. Edited by: Lumsden WHR, Evans DA. London: Academic Press; 1979:395-460.

26. Wilson VCLC, Southgate BA: Lizard Leishmania. In Biology of the Kinetoplastida Volume 2. Edited by: Lumsden WHR, Evans DA. London: Academic Press; 1979:241-268.

27. Poinar GO Jr, Poinar R: Fossil evidence of insect pathogens. J Invertebr Pathol 2005, 89:243-250.

28. Poinar GO Jr, Jacobson RL, Eisenberger CL: Early Cretaceous phlebotomine sand fly larvae (Diptera: Psychodidae). Proc Entomol Soc Washington 2006, 108:785-792.

29. Poinar G Jr: Early Cretaceous flagellates associated with fossil sand fly larvae in Burmese amber. Mem Inst Oswaldo Cruz 2007, 102:635-637.

30. Poinar GO Jr: The origins, acquisition and transmission of Leishmania in the distant past. Science and Culture 2007, 73:116-119.

31. Noyes HA, Morrison DA, Chance ML, Ellis JT: Evidence for a Neotropical origin of Leishmania. Mem Inst Oswaldo Cruz 2000, 95:575-578.

32. Kerr SF: Palaearctic origin of Leishmania. Mem Inst Oswaldo Cruz 2000, 95:75-80.

33. Poinar GO Jr: Plasmodium dominicana n. sp. (Plasmodiidae: Haemospororida) from Tertiary Dominican amber. Syst Parasitol 2005, $61: 47-52$.

34. Poinar GO Jr: Triatoma dominicana sp. n. (Hemiptera: Reduviidae Triatominae), and Trypanosoma antiquus sp. n. (Stercoraria: Trypanosomatidae), the first fossil evidence of a Triatomine-Trypanosomatid Vector Association. VectorBorne Zoonotic Dis 2005, 5:72-8I.

35. Iturralde-Vincent MA, MacPhee RDE: Age and Paleogeographic origin of Dominican amber. Science 1996, 273:1850-1852.

36. Schlee D: Das Bernstein-Kabinett. Stuttgarter Beitr Naturkunde, Ser. C 1990, 28: I-100.

37. Draper GP, Mann S, Lewis JF: Hispaniola. In Caribbean geology: an introduction Edited by: Donovan S, Jackson TA. Kingston, Jamaica: The University of the West Indies Publishers' Association; 1994:129-150.

38. Poinar GO Jr: Hymenaea protera sp. n. (Leguminosae, Caesalpinioideae) from Dominican amber has African affinities. Experientia 199|, 47:1075-1082.

39. Poinar GO >Jr, Poinar R: The Amber Forest Princeton: Princeton University Press; 1999.

40. McAlpine JF: Morphology and Terminology-Adults. In Manual of Nearctic Diptera. Monograph 27 Volume I. Edited by: McAlpine JF. Ottawa: Agr. Canada Res. Branch; 1981:9-63.
Publish with Biomed Central and every scientist can read your work free of charge

"BioMed Central will be the most significant development for disseminating the results of biomedical research in our lifetime. "

Sir Paul Nurse, Cancer Research UK

Your research papers will be:

- available free of charge to the entire biomedical community

- peer reviewed and published immediately upon acceptance

- cited in PubMed and archived on PubMed Central

- yours - you keep the copyright
BioMedcentral 